\title{
Adhesion on Nanoorganized Multilayers: Surface Thermodynamics and Local Energy Dissipation
}

\author{
Yolla Kazzi, ${ }^{1}$ Houssein Awada, ${ }^{2}$ and Michel Nardin ${ }^{3}$ \\ ${ }^{1}$ Faculty of Sciences, Lebanese University, Hadath, BP 13-5789, Beirut, Lebanon \\ ${ }^{2}$ Institute of Condensed Matter and Nanosciences - Bio \& Soft Matter (IMCN-BSMA), Universitè Catholique de Louvain, \\ Croix du Sud 1 box 4, 1348 Louvain-la-Neuve, Belgium \\ ${ }^{3}$ Institut de Chimie des Surfaces et Interfaces, CNRS, 15 Rue Jean Starcky, BP 2488, 68057 Mulhouse, France \\ Correspondence should be addressed to Yolla Kazzi, ykazzi@ul.edu.lb
}

Received 4 December 2009; Revised 12 April 2010; Accepted 14 June 2010

Academic Editor: Samir K. Pal

Copyright ( 2010 Yolla Kazzi et al. This is an open access article distributed under the Creative Commons Attribution License, which permits unrestricted use, distribution, and reproduction in any medium, provided the original work is properly cited.

\begin{abstract}
Nanostructured multilayers, composed of alternate organic (3-mercaptopropyltrimethoxysilane, alkylthiols, polydimethylsiloxane) and metallic (gold) layers, are grafted onto glass and prepared in order to modify the mechanical and dissipative properties of a thin surface layer of the substrate. The external face is constituted either of gold or alkyl groups, allowing us to study two types of surfaces exhibiting different chemical and thermodynamic properties. The formation and the structure of the nanostructured multilayers are first examined by means of various techniques such as atomic force microscopy (AFM), wettability, X-ray photoelectron spectroscopy (XPS), and conductivity measurements. All the results concerning the structure of the systems studied are used to understand the adhesive properties at short contact times (tack) of the multi-layers and an elastomer (polyisoprene). The influence of the structural aspects of gold layers, the length of the alkyl chains of the top layer, the terminal functionality, and the length of the confined organic layer between two gold layers on the energy of adhesion regarding the polyisoprene are clearly demonstrated. The influence of the nano-structured surface layers on adhesion phenomena is explained in terms of either the surface thermodynamics or local energy dissipation during the propagation of a fracture according to complex mechanisms.
\end{abstract}

\section{Introduction}

The adhesive characteristic of a material under low pressure and at a very short contact time is called "tack" [1]. Tack is of considerable practical interest in the fields of adhesives and bonding, particularly for pressure-sensitive adhesives (PSAs), for example, self adhesive labels.

The use of adhesives has become more and more frequent and their use in extremely diverse fields demands a deeper understanding of the mechanisms governing their properties.

In earlier research, numerous studies have attempted to clearly understand the role of various molecular (chemical structure, surface energy, composition) [2-4], experimental (contact time, contact pressure, temperature) $[5,6]$, or topological (sample roughness and thickness) [7] parameters, on the tack properties of pressure-sensitive adhesives (PSAs).

Tack is determined by measuring the energy required to separate materials. However, the measured energy of adhesion can be several orders of magnitude higher than the thermodynamic work of Dupré [8] (reversible energy of adhesion). This apparent discrepancy arises from dissipation mechanisms occurring in the materials during their separation: viscoelastic losses, plastic deformation, cavitation, and so forth, depending on the type of materials and systems. The dissipation can be limited to a region close to the interface (local dissipation) or extended to nearly all the material (bulk dissipation). In the present study, controlled contact conditions are used in such a way that dissipation takes place only in a region close to the interface. Until now the coupling between dissipation and interfacial interactions is not well understood, and particularly, it is not really known to what extent a thin film deposited on the surface of a rigid substrate can affect the dissipation mechanisms involved during adhesion measurements. To perform fundamental investigations, the use of well-defined surfaces is necessarily required. Model surfaces (multilayers) can be obtained by grafting alternating layers of gold and 


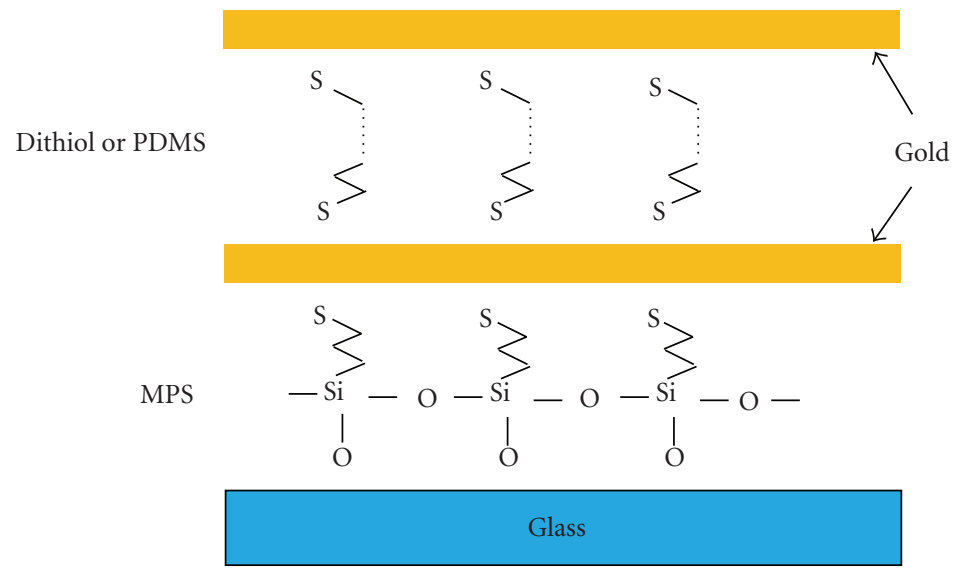

FIGURE 1: Schematic representation of the nanostructured multilayers. The scale between molecules and gold layers is not portional.

alkanethiol or polydimethylsiloxane on smooth materials, that is, glass plates. The external face is either a gold or alkyl group (by using an alkylthiol for the final layer). These types of surface exhibit different chemical and thermodynamic properties.

The characterization of nanostructured multilayers and the influence of such complex on tack of cross-linked elastomers have been studied in the preceding papers [9, 10].We complete this characterization from a chemical as well as a structural point of view by means of various techniques, such as X-ray photoelectron spectroscopy (XPS), atomic force microscopy (AFM), wetting measurements, and ellipsometry. Moreover, electrical conductivity measurements of gold layers are also carried out to analyze more precisely their morphology.

In the present study, the number of layers, the nature of the top surface layer (gold or alkanethiol molecules), the length of the alkyl chains of the top layer (hexadecanethiol or hexanthiol molecules), the terminal functionality, and the length of the confined organic layer between two gold layers and the thickness of the first gold layer are varied.

The adhesion energy is then evaluated between the different planar substrate (glass plate) supporting the nanostructured multilayers and a crosslinked elastomer (polyisoprene) as a function of compression force imposed before separation.

Tack evaluation allows us to control experimental parameters such as speed and contact time and also to minimize as far as possible viscoelastic loss.

In our study we focus our attention on the characterization of the system containing polydimethylsiloxane in order to compare between tack tests performed on different confined organic layers.

\section{Marerials and Methods}

2.1. Preparation of Nanostructured Multilayers. The multilayers are prepared in the following way [10]. After ultrasonic cleaning in chloroform, the surface of a glass plate is hydroxylated by dipping it into a piranha solution $(30 \%$ $\mathrm{H}_{2} \mathrm{O}_{2} / 70 \% \mathrm{H}_{2} \mathrm{SO}_{4}$ ) at $50^{\circ} \mathrm{C}$ for 30 minutes. Glass plate is then rinsed with bidistilled water and dried under nitrogen gas jet.

For the first layer of gold, first we immersed glass slides (18 hours) in $1 \mathrm{~mol} \cdot \mathrm{l}^{-1}$ of 3-mercaptopropyltrimethoxysilane (MPS, 95\%) solution (in toluene). MPS (supplied by ABCR, Karlsruhe-Germany) was used as a coupling agent between glass slides and gold coatings [11, 12]. Second, grafted glass are rinsed with toluene and dried in $\mathrm{N}_{2}$ gas jet. Finally, the first gold (99.99\% from Blazers) layer was coated under vacuum $\left(10^{-7}\right.$ mbar $)$ using an Edwards 306 evaporator. The thickness of gold layers varies from about 2 to $100 \mathrm{~nm}$.

For the second layer of gold we have used two kinds of coupling agent, an alkythiol with thio-sulfur group at both ends and a polydimethylsiloxane (PDMS) of molecular weight of $1000 \mathrm{~g} \cdot \mathrm{mol}^{-1}$ and $3000 \mathrm{~g} \cdot \mathrm{mol}^{-1}$, respectively, called $\mathrm{PDMS}_{n=10}$ and $\mathrm{PDMS}_{n=37}$. The PDMS has amine end groups on both chain ends.

The sulfur and the amine are able to create a specific and strange link with the gold surface. In both cases, we immersed the substrates in a $1 \mathrm{mmol} \cdot \mathrm{l}^{-1}$ solution of either 1-9 nonanedithiol (95\%, Aldrich) or $\mathrm{PDMS}_{n=10}$ (from ABCR, Karlsruhe-Germany) in ethanol and $1 \mathrm{mmol} \cdot \mathrm{l}^{-1}$ solution of $\mathrm{PDMS}_{n=37}$ (from ABCR, Karlsruhe-Germany) in cyclohexane for 18 hours; then the substrates are rinsed with ethanol (in the case of alkylthiol, $\mathrm{PDMS}_{n=10}$ ) and with cyclohexane (in the case of $\mathrm{PDMS}_{n=37}$ ) and dried in an $\mathrm{N}_{2}$ gas jet.

The schematic structure of the multilayers, prepared in this study, is shown in Figure 1.

2.2. Characterization of the Multilayers. Surface morphologies of the different types of layers are studied by atomic force microscopy (AFM) (Nanoscope III) in the tapping mode.

Their surface energy is determined from static contact angle measurements (Krüss G2 system) of nonpolar (diiodomethane) and polar (water) liquids at room temperature [13].

The chemical composition of the surface is analysed by XPS spectrometry. XPS spectra are obtained by means of a LEYBOLD LHS 11 apparatus using non-monochromatised 


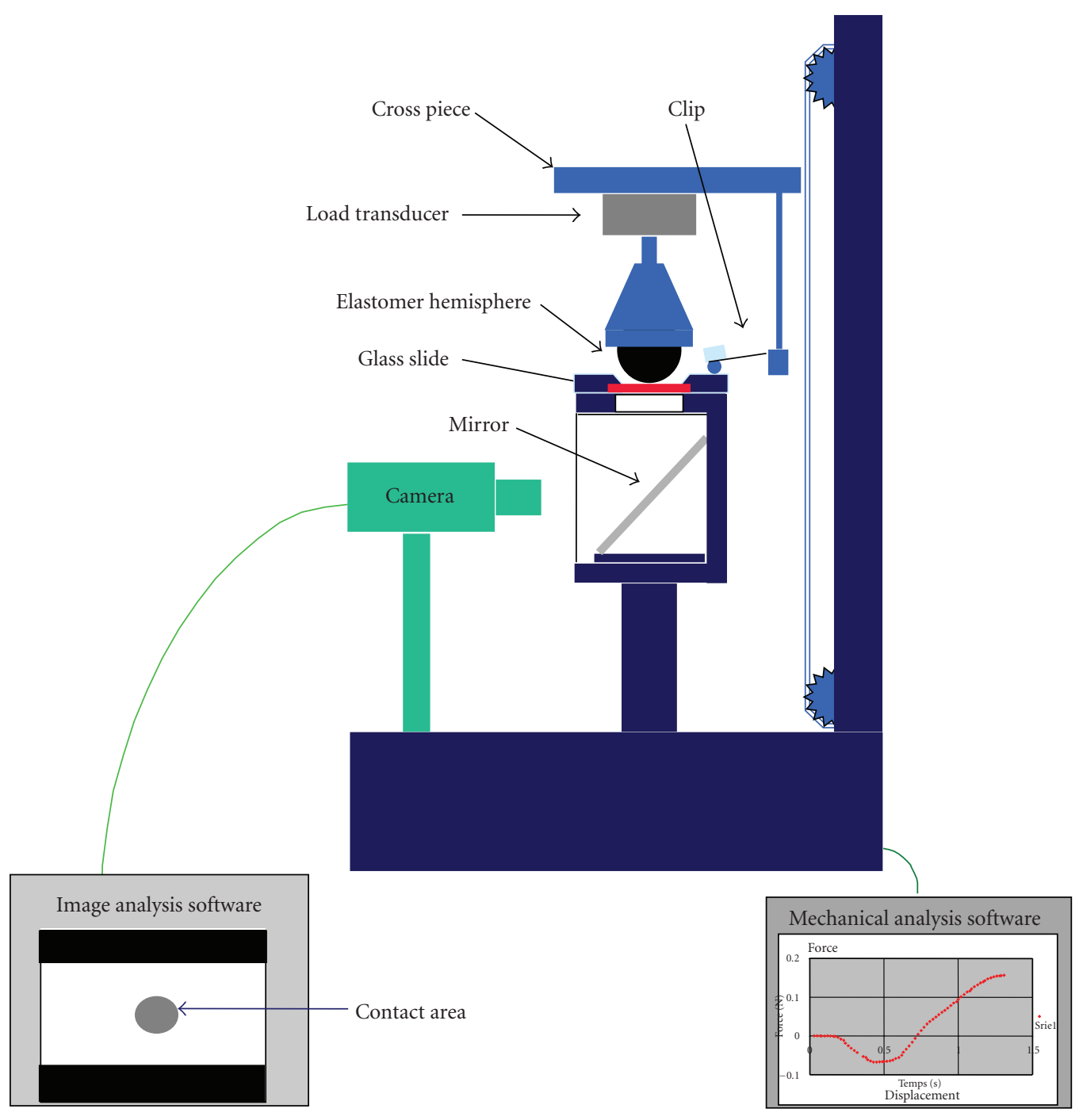

FIgURE 2: Test experimental setup.

$\operatorname{MgK} \alpha$ excitation radiation and at a take-off angle of $15^{\circ}$ in order to study a very thin surface layer, the thickness of which being less than $2 \mathrm{~nm}$.

Electrical resistivity measurements of gold layers are performed using the two-point-probe technique [14]. A mask with $3 \mathrm{~mm}$ width circular windows $(\Phi)$, separated by a distance "d" of $3 \mathrm{~mm}$, is used to carry out the deposition of several gold contact fingers (thickness of about $100 \mathrm{~nm}$ ) onto thin gold layers. The average resistance $\mathrm{R}$ of such layers (thickness " $\mathrm{e}$ ") is measured by subjecting them to an electrical current of 1 to $3 \mu \mathrm{A}$. The gold layer resistivity $\rho$ is therefore given by the following expression:

$$
\rho=\frac{R \Phi e}{d} .
$$

The time between preparation of multilayers and physicochemical analysis is usually less than one day the samples are meanwhile stored in a desiccator.

The thickness of the films is measured by spectral ellipsometry using a multiplayer optical spectrometric scanner model ES4M [15] operating at $633 \mathrm{~nm}$ and an angle of incidence of $75^{\circ}$. All ellipsometric thicknesses are the average of at least three independent measurements on each sample. The ellipsometric results are used to calculate the corresponding thickness values using the Elli 45 computer program.

2.3. Adhesion (Tack) Test. To evaluate tack for the systems glass/multilayers/elastomer, the Johnson, Kendall, and Roberts (JKR) test [16] was used. We have chosen the contact between a hemisphere of cross-linked polyisoprene and a plane substrate on which nanostructured multilayers are grafted. With this particular geometry, bulk dissipations are greatly reduced and the contact area can be easily measured. In our study the polyisoprene is partially crosslinked with dicumyl of peroxide [17]. With the apparatus described in (Figure 2), the impact and separation rates $\left(10 \mathrm{~mm} \cdot \mathrm{min}^{-1}\right)$ as well as the contact time can be controlled. A high-speed camera (250 image $\left.\cdot \mathrm{s}^{-1}\right)$ is used to follow the area of contact between the elastomer and the substrate. 

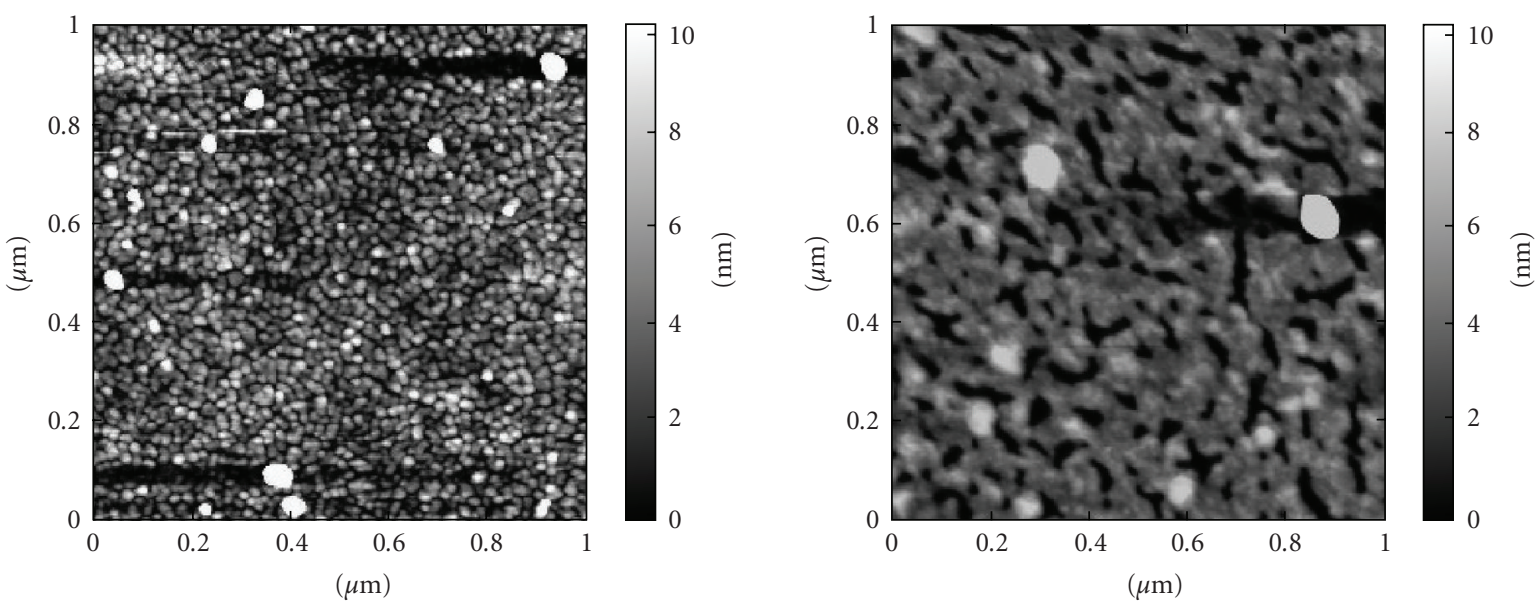

(a)

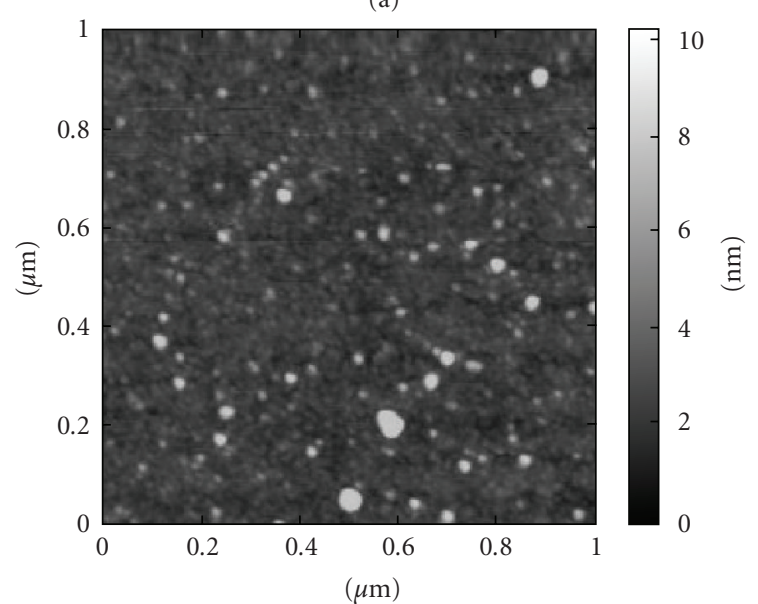

(b)

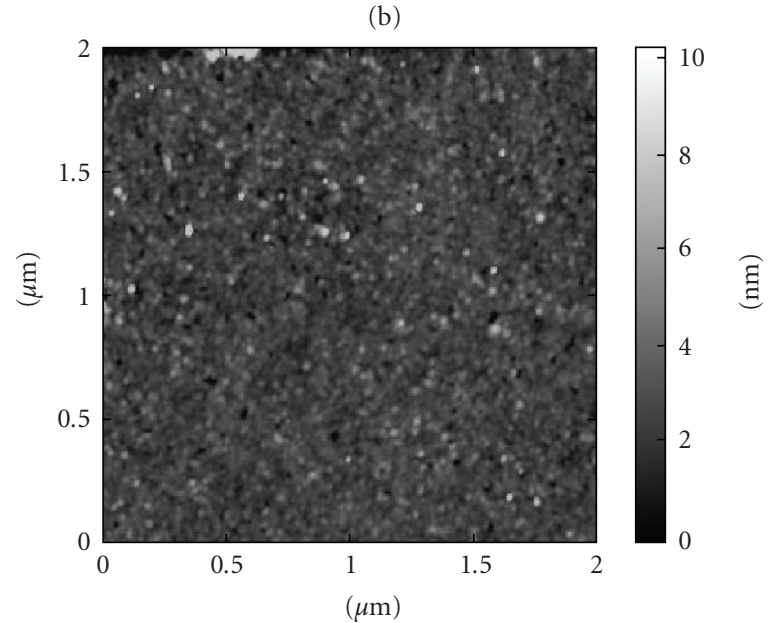

(c)

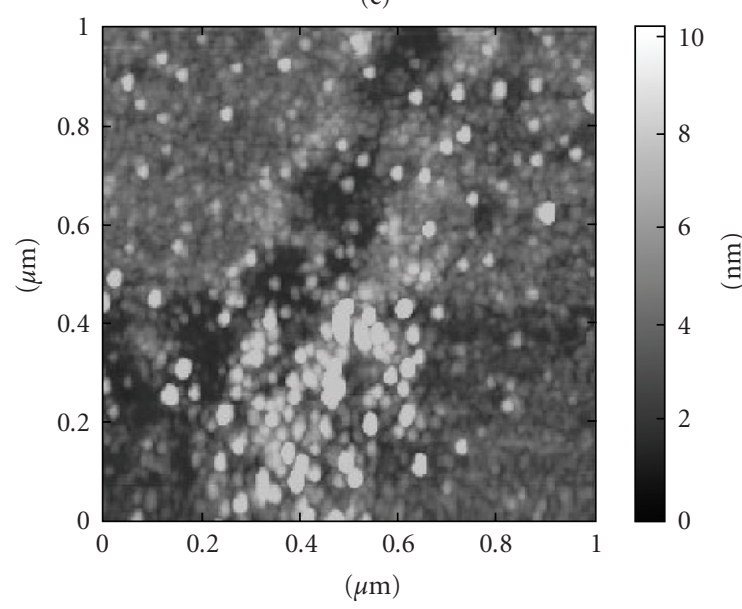

(d)

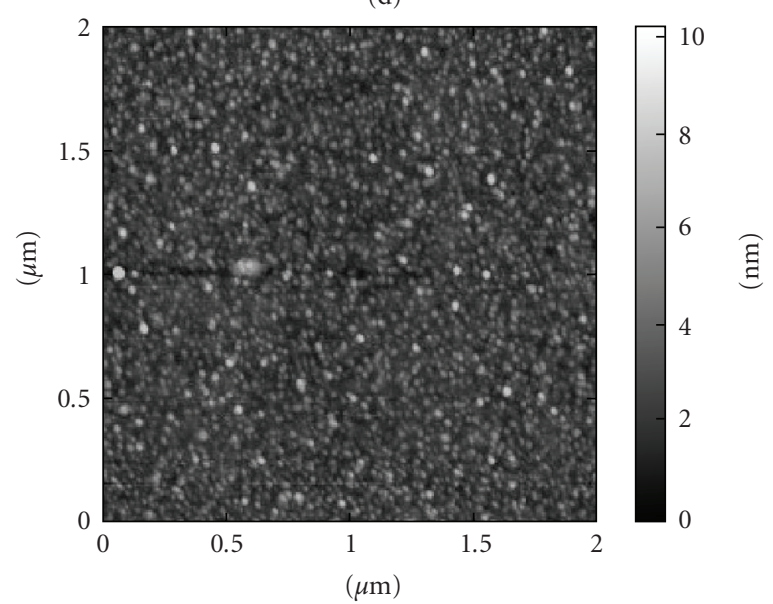

(e)

(f)

Figure 3: AFM images are determined in tapping mode: (a) $(1 \mu \mathrm{m} \times 1 \mu \mathrm{m})$ glass/MPS/gold $(5.7 \mathrm{~nm}) /$ dithiol; $(\mathrm{b})(1 \mu \mathrm{m} \times 1 \mu \mathrm{m})$ glass/MPS/gold $(5.7 \mathrm{~nm}) /$ dithiol/gold $(6 \mathrm{~nm}) ;(\mathrm{c})(1 \mu \mathrm{m} \times 1 \mu \mathrm{m})$ glass/MPS/gold $(5.25 \mathrm{~nm}) / \mathrm{PDMS}_{n=10} ;(\mathrm{d})(2 \mu \mathrm{m} \times 2 \mu \mathrm{m})$ glass/MPS/gold $(6.75 \mathrm{~nm}) / \mathrm{PDMS}_{n=10} /$ gold $(6.6 \mathrm{~nm}) ; \quad(\mathrm{e})(1 \mu \mathrm{m} \times 1 \mu \mathrm{m})$ glass/MPS/gold $(5.7 \mathrm{~nm}) / \mathrm{PDMS}_{n=37} ; \quad(\mathrm{f})(2 \mu \mathrm{m} \times 2 \mu \mathrm{m})$ glass/MPS/gold $(5.55 \mathrm{~nm}) / \mathrm{PDMS}_{n=37} /$ gold $(5.55 \mathrm{~nm})$. Scale in $\mathrm{z:} 10 \mathrm{~nm}$.

Thus, displacements, applied force, and contact area can be measured simultaneously.

The total energy to break the junction, $G_{\text {tot }}$, is obtained by integration of positive values of the force $F$ versus

displacement:

$$
G_{\mathrm{tot}}=\int_{F \geq 0} F \cdot d z
$$


It should be mentioned that the JKR theory cannot be used here because this theory applies to the equilibrium state and, in our case, the system is never at equilibrium.

\section{Results and Discussion}

\subsection{Characterization of Nanostructured Multilayers.}

3.1.1. Atomic Force Microscopy (AFM). Typical topographic AFM images of different multilayers grafted onto glass slides are presented in Figure 3 which represents, respectively, the dithiol, $\mathrm{PDMS}_{n=10}$, or $\mathrm{PDMS}_{n=37}$ as intermediate layers before and after deposition of the gold top layer.

The comparison of the root-mean-square roughness (rms) and the average height is deduced from $1 \mu \mathrm{m} \times 1 \mu \mathrm{m}$ images showing that the $\mathrm{PDMS}_{n=37}$ grafting (Figure 3(e)) is more heterogeneous than that of the $\mathrm{PDMS}_{n=10}$ (Figure 3(c)). Apparently the latter leads to a uniform deposit $(\mathrm{rms}$ roughness $=0.67 \mathrm{~nm})$ with aggregates of average height of $3 \mathrm{~nm}$.

The PDMS $_{n=37}$ (Figure 3(e)) deposits are more irregular $(\mathrm{rms}$ roughness $=1.4 \mathrm{~nm})$, they exhibit pit-like defects and aggregate approximately $4 \mathrm{~nm}$ in average height. They are scattered heterogeneously on the surface and are separated by small apparent gold areas.

AFM images of gold surface layer about $5 \mathrm{~nm}$ thick, deposited on the $\mathrm{PDMS}_{n=10}$ and $\mathrm{PDMS}_{n=37}$ display a granular gold structure. It is noted that the gold particles are circular and are estimated to be $20 \mathrm{~nm}$ in diameter (Figures 3(d) and $3(\mathrm{e})$ ), different from the worm-like connected structure which is observed on dithiol (Figure 3(b)). Therefore, the gold layer deposited onto monolayers terminated by thiol or amine displays a morphology, which depends on the nature of the interaction gold-thiol or gold-amine in concordance with literature [18]. Moreover, in this case, the roughness of the gold film is low and equal to $1.14 \mathrm{~nm}$.

3.1.2. Wetting Analysis (Contact Angle Measurements). Wetting analysis is used to characterize the surface after each chemical modification step. From the values of the contact angle measurements, both the dispersive $\left(\gamma_{s}^{d}\right)$ and the nondispersive or the polar $\left(\gamma_{s}^{p}\right)$ components of the different modified surfaces are calculated according to classical wettability analysis [11] and are presented in Table 1.

We observed a difference between the different surfaces. Moreover, for the same chemical composition and different multilayer composition we observed a difference in the thermodynamic properties. This difference is due to the morphologies of each surface [19].

The second gold layer deposited on polydimethylsiloxane exhibits values of the dispersive and polar components of surface energy $\left(\gamma_{s}^{d}\right.$ and $\gamma_{s}^{p}$ ) in contrast to those that are obtained on a continuous and smooth gold surface $\left(\gamma_{s}^{d}\right.$ $=40 \mathrm{~mJ} \cdot \mathrm{m}^{-2}$ and $\left.\gamma_{s}^{p}=1 \mathrm{~mJ} \cdot \mathrm{m}^{-2}\right)$. Therefore, the second gold deposit of $5 \mathrm{~nm}$ contributes to a slight increase in the hydrophobic nature of the surface but this is still insufficient to completely cover the PDMS layer grafted onto the underlying first gold layer.
3.1.3. X-Ray Photoelectron (XPS). Figure 4 shows the large spectra obtained for the multilayers containing PDMS. The peak $\mathrm{N}(1 \mathrm{~s})$ signal after grafting has been too weak to reveal the chemical state of the amine groups.

The fact that the element percentage of nitrogen $(\mathrm{N})$, oxygen $(\mathrm{O})$, and Silicon $(\mathrm{Si})$ increases after depositing the second gold layer (Table 3 ) means that the $\mathrm{PDMS}_{n=10}$ layer is not completely covered by a gold layer $5 \mathrm{~nm}$ thick. This observation is consistent with a structure in which the PDMS molecules are distributed randomly on the gold surface as "pelote" conforming with wetting and ellipsometric results, which show the heterogeneity of the gold surface and the spread out conformation of PDMS molecules.

Concerning $\mathrm{PDMS}_{n=37}$ the comparisons between ratios of different elements $(\mathrm{N}, \mathrm{O}, \mathrm{Si})$ before and after depositing the second gold layer suggest a more regular uniform gold layer on PDMS ${ }_{n=37}$ molecules which appears to cover more $\mathrm{PDMS}_{n=37}$ than $\mathrm{PDMS}_{n=10}$ molecules.

The exact nature of the amine-Au interaction remains enigmatic. Yet several Au (I)-amine complexes have been reported [20]. According to some authors there may be a reaction between $\mathrm{Au}$ atomic vapor and amines, which is not found for bulk Au in contact with alkylamines $\mathrm{C}_{\mathrm{n}} \mathrm{H}_{2 \mathrm{n}+1}(\mathrm{n}=$ $10,12,16$, and 18) adsorbed from solution [18].

3.1.4. Ellipsometry. The low thickness value of the multilayer having terminal PDMS layer (i.e., PDMS $_{n=10}=0.55 \mathrm{~nm} \pm$ 0.06 and $\left.\mathrm{PDMS}_{n=37}=0.45 \mathrm{~nm} \pm 0.04\right)$ as it is determined by ellipsometry is consistent with the randomly structure of PDMS representative of a grafted surface which is not uniform as it is suggested by wetting, XPS data, and atomic forces microscopy observations in previous sections.

To the best of our knowledge several studies on alkylthiol monolayers have been reported in literature, but today few data deal with monolayers formed by PDMS molecules, which is why we are not able to compare our data to those of literature.

3.1.5. Conductivity Measurements. Conductivity measurements are carried out on the PDMS layer involving two successive gold layers (glass/MPS/gold/PDMS ${ }_{n=37} /$ gold) with a varying thickness. Two sets of values of the resistivity $\rho$ are obtained according to (1) by taking into account either the thickness of the second gold layer only or the sum of the thickness of both gold layers (Figure 5). Three curves are represented in Figure 5. The curve 1 (master curve) represents the variation of the electrical resistivity $\rho$ (obtained according to (1)) of the first gold layer as a function of its thickness (log-linear plot). The curve $2 \mathrm{~b}$ represents the variation of the electrical resistivity $\rho$ (obtained according to (1)) of the second gold layer as a function of its thickness. The curve $3 \mathrm{a}$ represents the variation of the $\log$ resistivity $\rho$ (obtained according to equation (1)) obtained by taking into account the sum of the thicknesses of the two successive gold layers.

It appears on the one hand that the thickness of the second layer cannot be only considered to determine the resistivity of the given systems, since the values obtained (curve 2, Figure 5) are much lower than those constituting the master 


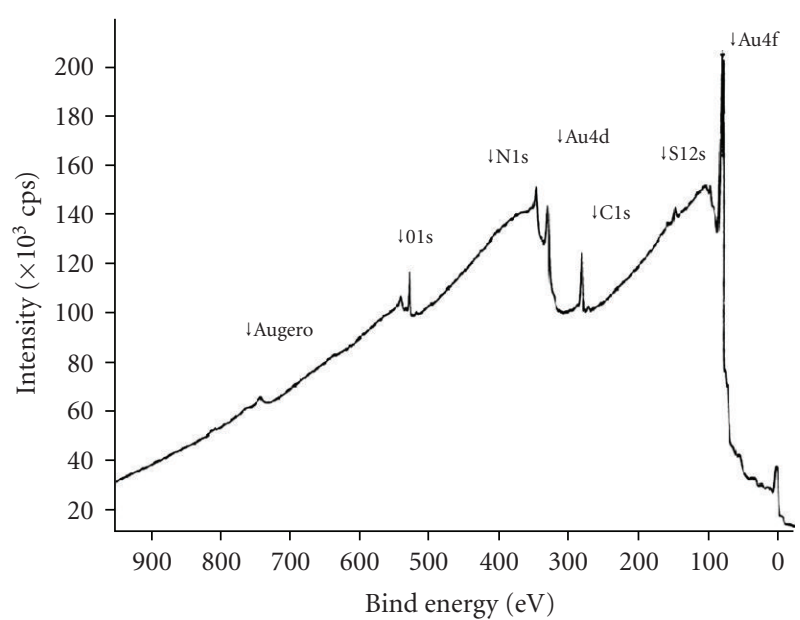

(a)

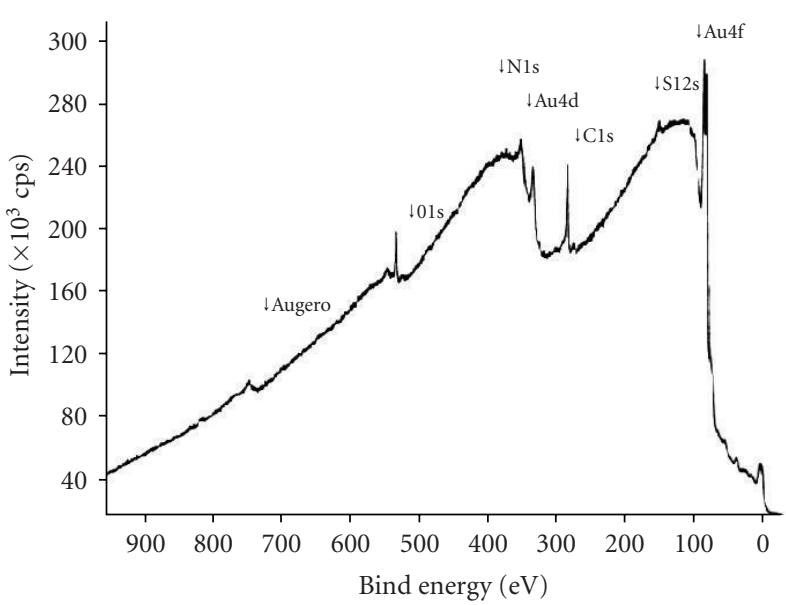

(b)

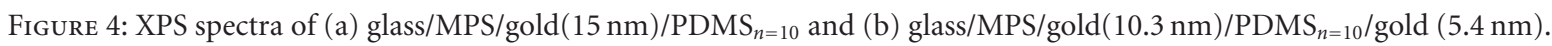

TABLE 1: Dispersive $\gamma^{d}$ and polar $\gamma^{p}$ components of the surface energy of materials studied.

\begin{tabular}{|c|c|c|c|}
\hline & $\gamma_{s}^{d}\left(\mathrm{~mJ} \cdot \mathrm{m}^{-2}\right) \pm 2$ & $\gamma_{s}^{p}\left(\mathrm{~mJ} \cdot \mathrm{m}^{-2}\right) \pm 2$ & $\gamma_{s}\left(\mathrm{~mJ} \cdot \mathrm{m}^{-2}\right) \pm 2$ \\
\hline glass/MPS/gold/hexadecanethiol & 24 & 1 & 25 \\
\hline glass/MPS/gold/hexanethiol & 47 & 1 & 48 \\
\hline glass/MPS/gold/dithiol/gold/hexadecanethiol & 28 & 2 & 30 \\
\hline glass/MPS/gold/dithiol/gold/hexanethiol & 42 & 1 & 43 \\
\hline glass/MPS/gold/PDMS ${ }_{n=37}$ & 38 & 2 & 40 \\
\hline glass/MPS/gold/PDMS ${ }_{n=10}$ & 31 & 1 & 32 \\
\hline glass /MPS/gold/dithiol/gold & 50 & 2 & 52 \\
\hline glass/MPS/gold/PDMS ${ }_{n=37} /$ gold & 39 & 1 & 40 \\
\hline${\text { glass} / \mathrm{MPS} / \text { glass } / \mathrm{PDMS}_{n=10} / \text { gold }}$ & 28 & 4 & 32 \\
\hline Polyisoprene (IR) & 27 & 3 & 30 \\
\hline
\end{tabular}

curve as it is determined previously (curve 1, Figure 5). On the other hand a total connection between these two gold layers is not really achieved since too high values (curve 3, Figure 5) of the resistivity might now be obtained.

In spite of the fact that the resistivity curves shifted to a slight thickness (Figure 5 (2b), and (3b)) in concordance with some data of the literature [18] indicating a threshold percolation in such systems lower than that concerning the thiol, around $2 \mathrm{~nm}$ instead of $5 \mathrm{~nm}$, the results are comparable to those obtained previously [10] for the dithiol layer involving two successive gold layers (glass/MPS/gold/dithiol/gold). We obtained intermediary resistivity values between the values for the first layer and those corresponding to the thickness of the two layers together.

These results show a partial connection between the gold layers which theoretically should have been isolated from an electric point of view and independently of the length of PDMS molecule chains.

3.2. Tack. Tack between the nanostructured multilayers and the cross-linked polyisopren hemisphere is evaluated by varying the maximum force of compression (Figures 6, 7, and 8). As expected, tack energy increases with maximum compression because contact area increases too.

More noteworthy is the variation of tack energy as a function of the structure of the multilayers.

In previous study [9] it appears that the tack energy depends on the nature of the layers: the substrates terminated by one gold layer lead to a higher tack energy than substrates with an external surface composed of methyl groups.

In the present study we are interested first of all in the alkylthiol chain length.

3.2.1. Influence of Alkylthiol Chain Length of the Top Layer. At a very short time $0.1 \mathrm{~s}$ total energy of adhesion of elastomer/glass terminated by hexadecanethiol is slightly higher than the results obtained with hexanethiol-terminated glass. The same observation is reported in a system including two intermediate gold layers terminated by alkylthiol.

How can this difference be explained?

Let us suppose first of all that the difference is due to the fact that the surface energy is not identical for both kinds of molecules. Alkylthiol-terminated glass samples do 
TABLE 2: Reversible energy of adhesion elastomer-substrate.

\begin{tabular}{lc}
\hline & Reversible energy of adhesion $\left(W_{0}\right)\left( \pm 4 \mathrm{~mJ}^{\left.-\mathrm{m}^{-2}\right)}\right.$ \\
Interface & IR \\
\hline glass/MPS/gold/hexadecanethiol & 54 \\
glass/MPS/gold/hexanethiol & 74 \\
glass/MPS/gold/dithiol/gold/hexadecanethiol & 60 \\
glass/MPS/gold/dithiol/gold/hexanethiol & 71 \\
glass /MPS/gold/ dithiol/gold & 78 \\
glass/MPS/gold/PDMS & \\
glass/MPS/glass/PDMS & \\
\hline
\end{tabular}

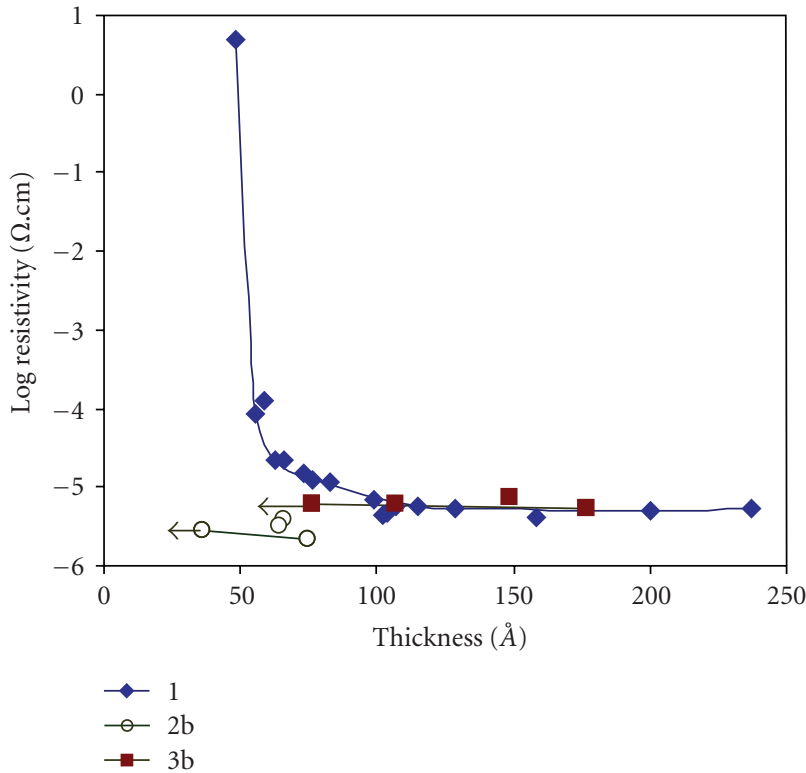

FIGURE 5: Variation of the resistivity of multilayers involving two gold layers compared to that of a monolayer of gold. Curve 1: results are given in Figure 5 for a mono-layer; Curve 2: variation obtained by considering the thickness of the second gold layer only; Curve 3: variation obtained by taking into account the sum of the thicknesses of the two successive layers.

not have the same surface energy; therefore their behaviour toward elastomer must be different. Hexanethiol grafting cannot reduce the dispersive component of the surface energy and thus total surface energy at the same proportion as hexadecanethiol.

The substrates used are listed in Table 1 together with the surface tension $\gamma_{s}$ and the nonpolar and polar components from $\gamma_{s}^{d}$ and $\gamma_{s}^{p}$.

Reversible energy of adhesion $\mathrm{W}_{0}$ is calculated by using (3) $[21]$ :

$$
W_{0}=2 \sqrt{\gamma_{1}^{d} \gamma_{2}^{d}}+2 \sqrt{\gamma_{1}^{P} \gamma_{2}^{P}}
$$

where $\gamma_{1}^{d}$ and $\gamma_{2}^{d}$ are the dispersive and polar components of the surface energy of solids 1 and 2 . The values obtained for different samples are shown in Table 2.

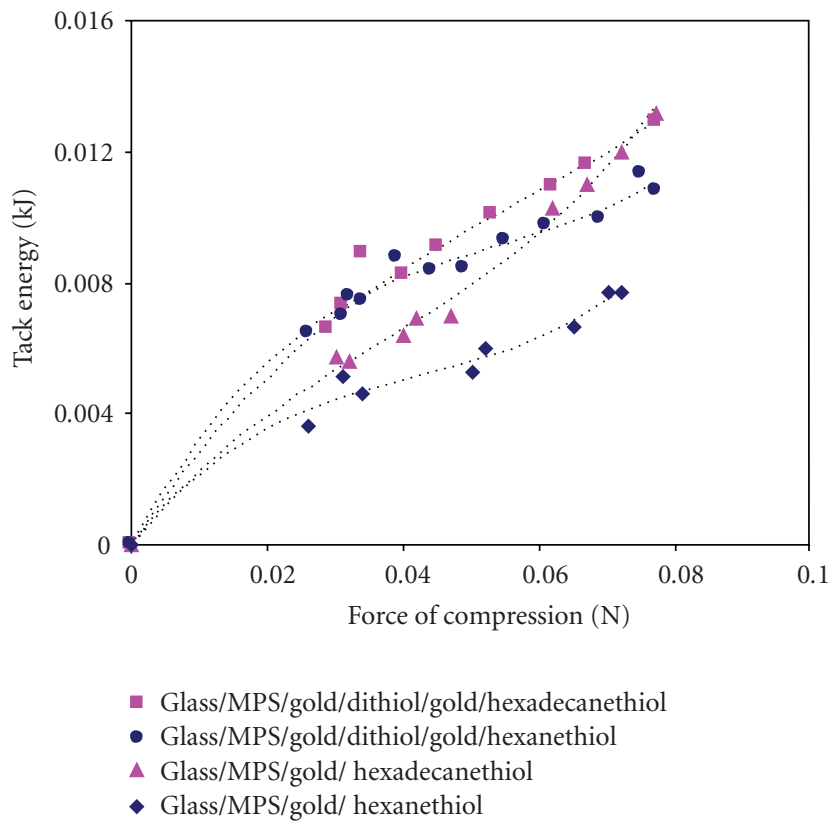

FIGURE 6: Variation of the total tack energy (in kJ) as a function of maximum compression.

Table 2 shows the reversible energy of adhesion evolution $W_{0}$ as a function of substrate according to the following order: Glass/MPS/gold/hexanethiol > glass/MPS/gold/ hexadecanethiol and glass/MPS/gold/dithiol/ hexanethiol > glass/MPS/gold/dithiol/hexadecanethiol.

This classification does not correspond to that obtained for total energy of adhesion $G$ evolution as a function of substrate (Figure 6): glass/MPS/gold/hexadecanethiol $>$ glass/MPS/gold/dithiol/hexanethiol and glass/MPS/gold/ dithiol/hexadecanethiol > glass/MPS/gold/dithiol/gold/ hexanethiol.

In our case it is clearly a proportional relation between tack energy $G$ and thermodynamic energy of adhesion $W_{0}$ which does not apply to our system.

This apparent discrepancy of tack energy with increasing chain length cannot be explained by wetting differences but interdiffusion of short alkyl-chains segments present at the layer surface to the elastomer surface can be invoked.

For, with hexanethiol-terminated substrates, alkyl chains are very short and have a limited influence in diffusion 


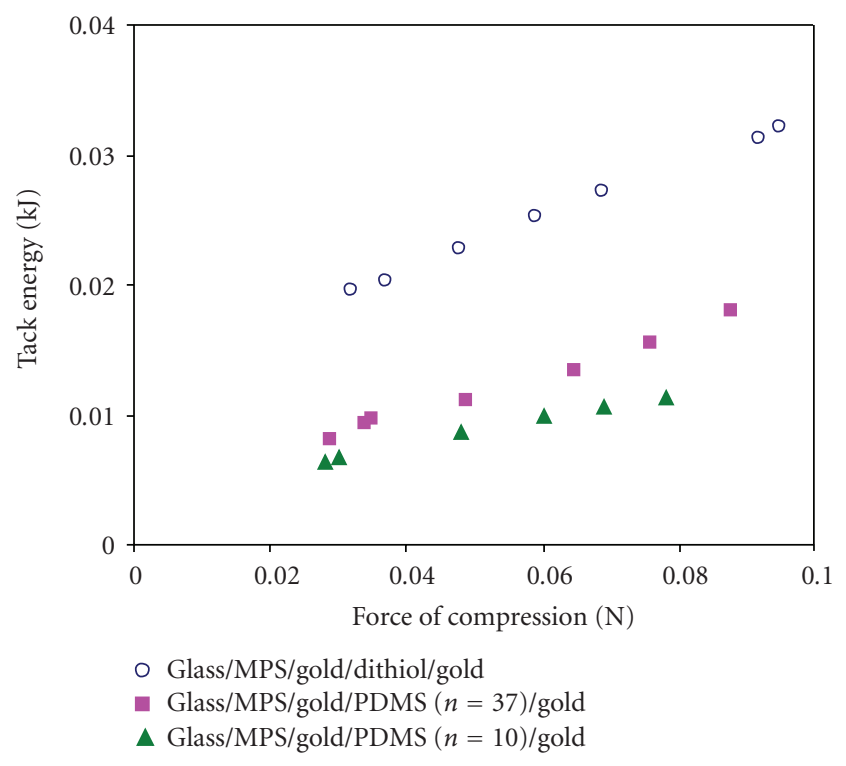

Figure 7: Variation of the total energy (in $\mathrm{kJ}$ ) as a function of maximum compression.

phenomenon, in the case of hexadecanethiol the chains are longer with sufficient mobility they diffuse at least part of the elastomer network.

This hypothesis is in concordance with results known from literature [22-24] where, according to the authors, diffusion of polymer chains will occur within a short period of time when two polymers are brought into close contact.

O'Connor and Leich [25] have shown that the penetration time of a polymer chain segment is very fast (about $0.1 \mathrm{~ms}$ for a polymeric chains containing $10^{3}$ monomers units).

In our case $(0.1 \mathrm{~s})$ it is more probable that a diffusion phenomenon of alkyl-chain segments in polyisoprene contributed significantly to increased adhesion energy.

A previous study about adhesion energy between elastomer and different silane lengths of alkyl-chains (from $\mathrm{C}_{4}$ to $\mathrm{C}_{30}$ ) on grafted glasses has shown clearly an increase of $\mathrm{G}$ with the length of alkyl-chains grafted.

In fact, the necessary condition for a diffusion of alkylchains (or chain segments) is the compatibility of these chains toward polyisoprene. In other words similar parameters of solubility are necessary to facilitate interpenetration of molecules in the contact area.

Values of solubility parameters of hexanethiol $\left(7(\mathrm{Mpa})^{0.5}\right)$, hexadecanethiol $\left(6.7(\mathrm{Mpa})^{0.5}\right)$, and of polyisoprene IR $\left(7.4(\mathrm{Mpa})^{0.5}\right)$ are very close, suggesting that interdiffusion phenomenon contributes to increase the adhesion of polyisoprene IR/alkylthiol-grafted substrates.

However, this increase is still very weak and other explications should be looked for. Indeed, the length of alkyl chains might affect the fracture propagation during separation, for example, by Shearing effects (parallel or perpendicular at the bottom of the crack) or by deformation of the grafted layer. Unfortunately such hypotheses cannot be confirmed by direct observation of the contact area evolution

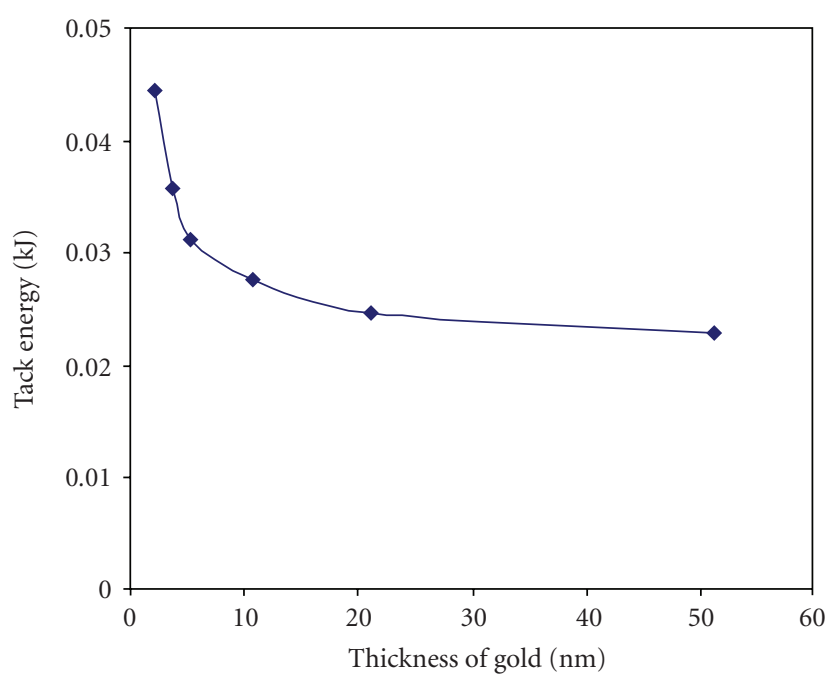

FIGURE 8: Total adhesion energy determined with the JKR geometry and evolution as a function of thickness of gold for a maximum compression of $0.04 \mathrm{~N}$.

during the time of tack measure. A local analysis of fracture propagation will also constitute a major development in our test.

The experimental data clearly shows that adherence level (tack) is controlled not only by surface energy of samples in contact but also by the interdiffusion phenomenon of short chain segments, at the beginning of contact, and the effect of the chain length on the fracture propagation at the interface polyisoprene/grafted glass will also play an important role.

3.2.2. Influence of the Terminal Functionality and the Length of the Confined Organic Layer between Two Gold Layers. To prove the influence of the nature and the chain length of intermediary molecules on measures of elastomer/glassgrafted terminated gold, we have chosen to use dithiols and polydimethylsiloxane $\mathrm{NH}_{2}$ molecules of different length.

Figure 7 shows the replacement of a dithiol intermediate layer by $\mathrm{PDMS}_{(n=10)}$ or $\mathrm{PDMS}_{(n=37)}$ and induces a notable decrease of tack energy.

However, the total tack energy is higher in the case of the $\operatorname{PDMS}_{(n=37)}$ layer than the system containing $\mathrm{PDMS}_{(n=10)}$.

In order to explain such results it is advisable to remember at first that a gold film deposited on dithiol shows a wormlike structure different from the granular structure observed when a gold film is deposited on amine in particular modified PDMS.

XPS and wetting studies reveal a heterogeneous gold surface deposited on PDMS molecules where the presence of this latter is still very pronounced.

The different tack energy evolution might be attributed to the presence of PDMS molecules at the surface, which do not contribute to the improvement of the adhesion because their interactions with elastomer are very weak.

Furthermore, the gold surface does not exhibit the same reversible energy of adhesion $\mathrm{W}_{0}$. The decrease of $\mathrm{W}_{0}$ from the sample of glass/MPS/gold/dithiol/gold 
TABLE 3: Normalized areas, atomic percentages, and atomic report are obtained by XPS analysis, of different samples: (a)

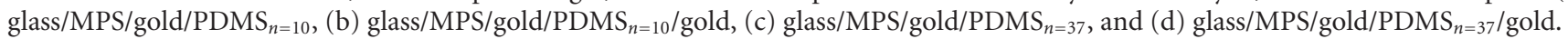

\begin{tabular}{|c|c|c|c|c|}
\hline & $\begin{array}{l}\operatorname{PDMS}_{(n=10)} \\
\text { grafted on gold layer } \\
\text { (a) }\end{array}$ & $\begin{array}{c}\operatorname{PDMS}_{(n=10)} \\
\text { covered by gold layer } \\
\text { (b) }\end{array}$ & $\begin{array}{l}\operatorname{PDMS}_{(n=37)} \\
\text { Grafted on gold layer } \\
\text { (c) }\end{array}$ & $\begin{array}{c}\operatorname{PDMS}_{(n=37)} \\
\text { covered by gold layer } \\
\text { (d) }\end{array}$ \\
\hline Normalised area C1s (cps eV) & 96500 & 74300 & 163200 & 184350 \\
\hline Normalised area O1s (cps eV) & 30541 & 36377 & 42131 & 24115 \\
\hline Normalised area N1s (cps eV) & 2213 & 2601 & 6431 & 2669 \\
\hline Normalised area Si 2p (cps eV) & 16487 & 18092 & 18374 & 13374 \\
\hline Normalised area $\mathrm{Au} 4 \mathrm{f}$ (cps eV) & 35447 & 27553 & - & 46816 \\
\hline$\%$ carbon & 53.3 & 46.8 & 70.9 & 67.9 \\
\hline \% oxygen & 16.9 & 22.9 & 18.3 & 8.9 \\
\hline$\%$ nitrogen & 1.2 & 1.6 & 2.8 & 1 \\
\hline \% Silicon $(\mathrm{Si})$ & 9.1 & 11.4 & 8 & 4.9 \\
\hline$\%$ gold & 19.6 & 17.3 & - & 17.3 \\
\hline $\mathrm{C} / \mathrm{Si}$ & 5.85 & 4.11 & 8.88 & 13.78 \\
\hline $\mathrm{Si} / \mathrm{N}$ & 7.45 & 6.96 & 2.86 & 5.01 \\
\hline $\mathrm{Au} / \mathrm{Si}$ & 2.15 & 1.52 & - & 3.50 \\
\hline $\mathrm{Au} / \mathrm{N}$ & 16.02 & 10.59 & - & 17.54 \\
\hline $\mathrm{O} / \mathrm{Si}$ & 1.85 & 2.01 & 2.29 & 1.80 \\
\hline
\end{tabular}

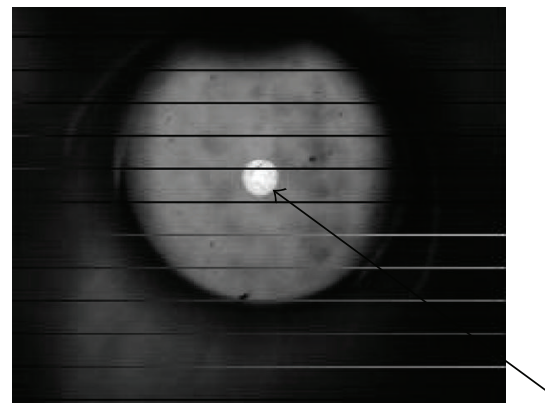

(a)

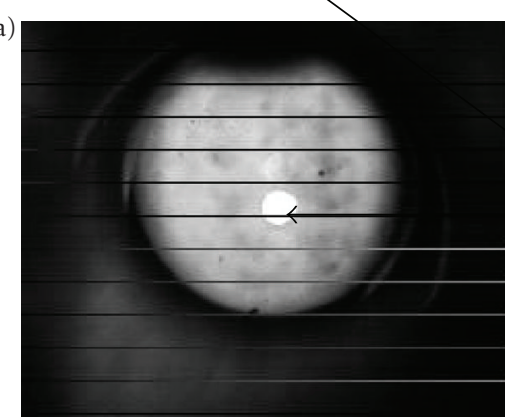

(c)

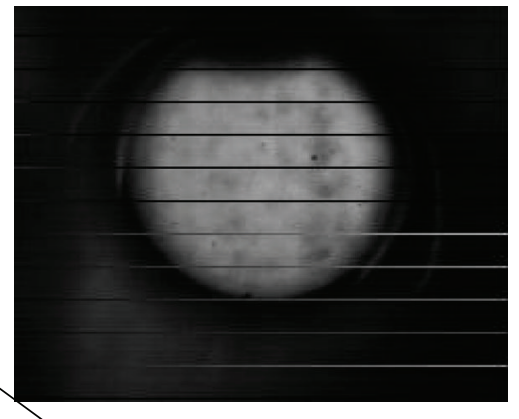

(b)

FIGURE 9: Images of contact area for different gold layer thickness (System IR/glass/MPS/gold): (a) $2.9 \mathrm{~nm}$, (b) $5.7 \mathrm{~nm}$, and (c) $10.8 \mathrm{~nm}$.

to glass/MPS/gold/PDMS ${ }_{n=37} /$ gold and glass/MPS/glass/ $\mathrm{PDMS}_{n=10}$ /gold, Table 2, means, in terms of physicochemical interactions, that the gold layers in the case of dithiol show a more favourable structure to wetting by polyisoprene, giving a higher tack energy.

It is shown that the length of the PDMS molecule chains can also influence tack energy.
As the tack energy in the case of $\mathrm{PDMS}_{(n=37)}$ is higher than that in the case of $\operatorname{PDMS}_{(n=10)}$, this means that a higher percentage of $\operatorname{PDMS}_{(n=10)}$ molecules at the surface is very important leading to a decrease in the interactions with elastomer.

Another hypothesis is that the length of molecular chains used as «separator» between the two successive gold layers 
seems to play an important role in energy dissipation or in fracture propagation during separation.

3.2.3. Influence of the Thickness of the First Gold Layer. For only a single gold layer deposited on MPS-modified glass, it seems obvious that the tack energy is strongly affected by thickness «e» of this layer as illustrated in Figure 8.

For a given compression force of $0.04 \mathrm{~N}$ it appears that tack decreases with increasing gold thickness until a constant value is obtained when «e» exceeds $10 \mathrm{~nm}$. Figure 8 shows that the tack energy variation for a low gold layer thickness (lower than $10 \mathrm{~nm}$ ) is an important phenomenon (multiplication factor about 2). This type of variation can be explained by gold layer structure evolution observed in AFM and conductivity measure showing in particular a percolation transition about $5 \mathrm{~nm}$ thick.

Worm-like disjointed structure for a gold thickness under $5 \mathrm{~nm}$ and worm-like connected structure for a thickness over $5 \mathrm{~nm}$ might also strongly influence fracture propagation during separation.

It is necessary to emphasise that the percolation transition of about $5 \mathrm{~nm}$ creates a problem of contact area visualization by optic analyse.

Indeed, the image of a contact area for a gold thickness of $5.7 \mathrm{~nm}$ (Figure 9(b)) corresponding to critical thickness, beyond which we have a conductivity transition, shows a blurred, even invisible contact area different from the images observed for other thicknesses (Figures 9(a) and 9(c)).

Normally, contact areas are circular and defined by an intense white spot compared to other images.

\section{Conclusion}

This study clearly shows the importance of the composition of nanostructured multilayers on adhesion energy with regard to polyisoprene elastomer. It appears that this global energy greatly depends on the following:

(i) the nature and length of chains of the confined molecular layer between two gold layers: with dithiol a higher tack energy is obtained than that with PDMS; the latter is however higher in the case of $\mathrm{PDMS}_{n=37}$ layer than that for the system containing $\mathrm{PDMS}_{n=10}$;

(ii) the number of layers: an increasing evolution of tack energy with the number of intermediate gold layers;

(iii) the thickness of the gold layer: a decrease in tack energy with the thickness of the gold layer;

(iv) the length of alkylthiol molecular chains: adhesion energy of substrate terminated by hexadecanethiol is a slightly higher than that terminated by hexanethiol.

In this way we have shown that wetting phenomena, viscoelastic energy dissipation, and chain diffusion contributed to adhesion energy.

Moreover the fracture propagation at the elastomer/glass grafted interface seems to be affected by the topology of the gold layer and the length of alkylthiol chains.
In order to give a full interpretation of the structure of these multilayers and their adhesive properties with regard to elastomer, it would be useful in the future to use a completely homogeneous gold surface from colloidal gold, rigid molecules between successive gold layers, and others kinds of elastomers as well as elastomer mixtures.

\section{Acknowledgment}

The authors would like to express their thanks to the foundation of the mulhouse School of Chemistry for their financial support.

\section{References}

[1] F. H. Wetzel, "The characterization of pressure-sensitive adhesives," ASTM Bulletin, no. 221, pp. 64-68, 1957.

[2] W. Smitthipong, M. Nardin, J. Schultz, T. Nipithakul, and K. Suchiva, "Study of tack properties of uncrosslinked natural rubber," Journal of Adhesion Science and Technology, vol. 18, no. 12, pp. 1449-1463, 2004.

[3] A. Aymonier, E. Papon, G. Castelein, M. Brogly, and P. Tordjeman, "Influence of surface and bulk structures of acrylic PSA films onto their tack properties," Journal of Colloid and Interface Science, vol. 268, no. 2, pp. 341-347, 2003.

[4] A. Aymonier, D. Leclercq, P. Tordjeman, E. Papon, and J.-J. Villenave, "Control of structure and tack properties of acrylic pressure-sensitive adhesives designed by a polymerization process," Journal of Applied Polymer Science, vol. 89, no. 10, pp. 2749-2756, 2003.

[5] A. E. O'Connor and N. Willenbacher, "The effect of molecular weight and temperature on tack properties of model polyisobutylenes," International Journal of Adhesion and Adhesives, vol. 24, no. 4, pp. 335-346, 2004.

[6] N. Morel, PH. Tordjeman, J. Duwattez, and E. Papon, "Scaling properties of contact area of pressure-sensitive adhesives," Journal of Colloid and Interface Science, vol. 280, no. 2, pp. 374379, 2004.

[7] A. Chiche, C. Creton, Y. Chen, and V. Studer, "Rôle de la topographie de l'adhérent sur l'adhésion des PSA," in Proceedings of the "1lémes journées d'Etude sur l'adhésion $J A D^{\prime} H$, pp. 144-146, October 2001.

[8] A. N. Gent and J. Schultz, "Effect of wetting liquids on the strength of adhesion of viscoelastic materials," Journal of Adhesion, vol. 3, pp. 281-294, 1972.

[9] M. O. David, T. Gerriet, M. Nardin, and J. Schultz, "Nanostructured multilayers and their influence on tack of crosslinked elastomers," Langmuir, vol. 16, no. 18, pp. 7346-7350, 2000.

[10] Y. Kazzi, H. Awada, M.-O. David, and M. Nardin, "Characterization of nano-organized multilayers constituted by successive inorganic (gold) and organic (alkylthiols) layers," Surface and Interface Analysis, vol. 39, no. 8, pp. 691-697, 2007.

[11] H. Awada, G. Castelein, and M. Brogly, "Use of chemically modified AFM tips as a powerful tool for the determination of surface energy of functionalised surfaces "' Journal de Physique IV, vol. 124, pp. 129-134, 2005.

[12] H. Awada, G. Castelein, and M. Brogly, "Quantitative determination of surface energy using atomic force microscopy: the case of hydrophobic/hydrophobic contact and hydrophilic/hydrophilic contact," Surface and Interface Analysis, vol. 37, no. 9, pp. 755-764, 2005. 
[13] A. W. Neumann and R. J. Good, Surface and Colloid Science, R. J. Good and R. Stronberg, Eds., Plenum Press, New York, NY, USA, 1979.

[14] D. L. Allara, A. F. Hebrad, F. J. Padden, R. G. Nuzzo, and D. R. Falcone, "Chemically induced enhancement of nucleation in noble metal deposition," Journal of Vacuum Science and Technology A, vol. 1, no. 2, pp. 376-382, 1982.

[15] R. M. A. Azzam and N. M. Bashara, Ellipsometry and Polarized Light, Elsevier Science, Amsterdam, The Netherlands, 1977.

[16] K. L. Johnson, K. Kendall, and A. D. Roberts, "Surface energy and the contact of elastic solids," Proceedings of the Royal Society A, vol. 324, no. 1558, pp. 301-313, 1971.

[17] M. O. David, T. Nipithakul, M. Nardin, J. Schultz, and K. Suchiva, "Influence of nonrubber constituents on tack of natural rubber. I. At very short times of contact (pendulum test)," Journal of Applied Polymer Science, vol. 78, no. 8, pp. 1486-1494, 2000.

[18] D. J. Dunaway and R. L. McCarley, "Scanning force microscopy studies of enhanced metal nucleation: au vapor deposited on self-assembled monolayers of substituted silanes," Langmuir, vol. 10, no. 10, pp. 3598-3606, 1994.

[19] F. M. Fowkes, Contact Angle : Wettability and Adhesion, American Chemical Society, Washington, DC, USA, 1964.

[20] R. J. Puddephat, The Chemistry of Gold, vol. 16 of Topics in Inorganic and General Chemistry, R. J. H. Clark, Ed., Elsevier, Amsterdam, The Netherlands, 1978.

[21] D. H. Kaebele and K. C. Uy, "Reinterpretation of organic liquid-polytetrafluoroethylene surface interactions," The Journal of Adhesion, vol. 2, no. 1, pp. 50-60, 1970.

[22] S. S. Voiutskii, Autohesion and Adhesion of High Polymers, John Wiley \& Sons, New York, NY, USA, 1963.

[23] T. K. Bhaumik, A. K. Bhowmick, and B. R. Gupta, "Tack and green strength of EPDM and Bromobutyl rubber, PII unfilled Blends," Journal of Adhesion, vol. 24, pp. 183-198, 1987.

[24] A. Sarkar, M. L. Mukherjee, and A. K. Bhowmick, "Tack and diffusion of silicone and EPDM rubbers," Journal of Materials Science Letters, vol. 11, no. 13, pp. 924-927, 1992.

[25] K. P. O'Connor and T. C. B. McLeish, "“Molecular velcro": dynamics of a constrained chain into an elastomer network," Macromolecules, vol. 26, no. 26, pp. 7322-7325, 1993. 


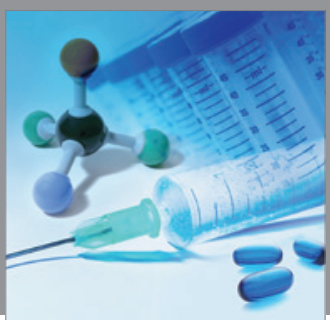

International Journal of

Medicinal Chemistry

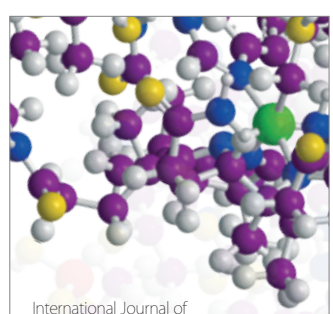

Carbohydrate Chemistry

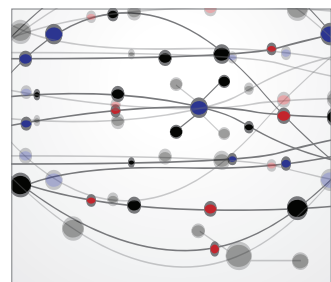

The Scientific World Journal
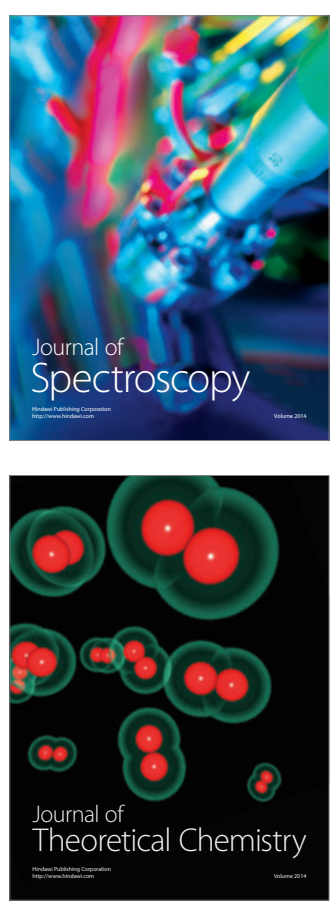
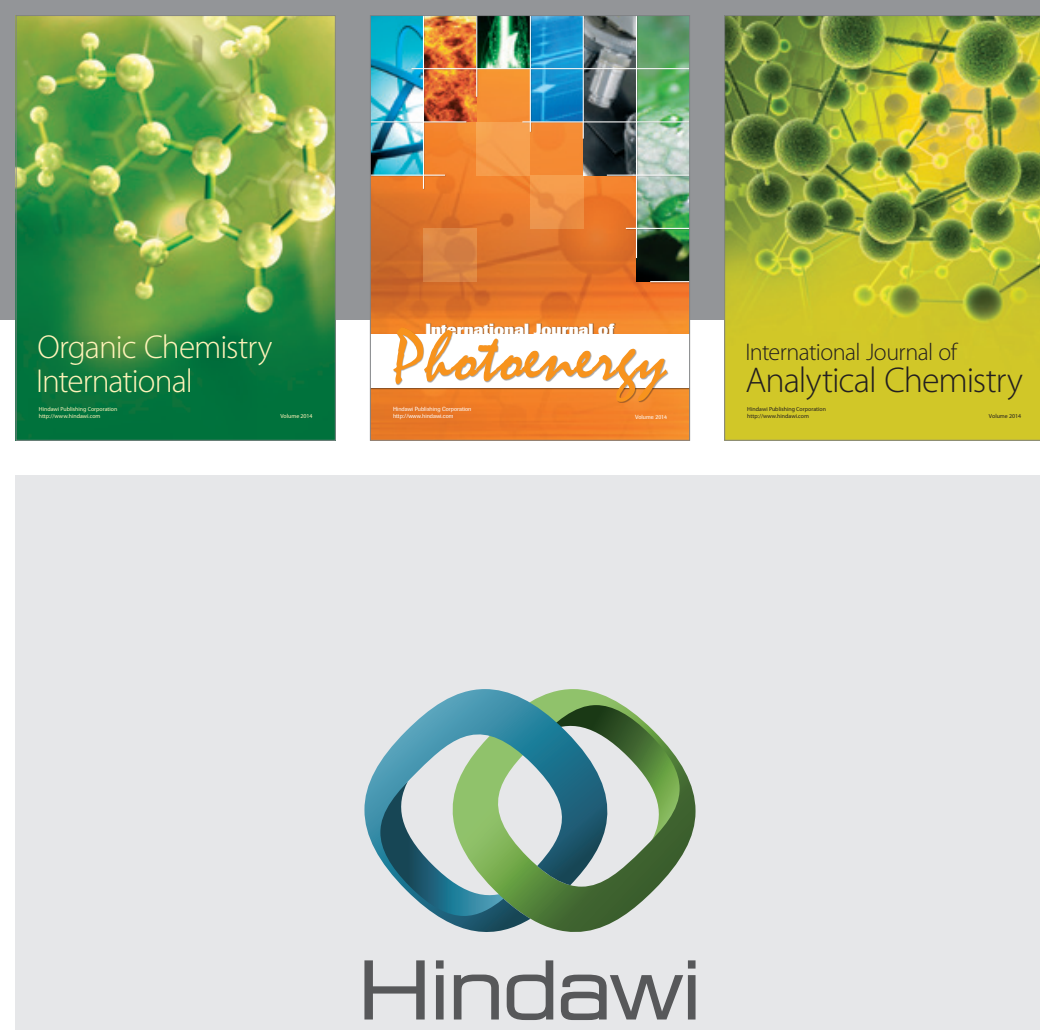

Submit your manuscripts at

http://www.hindawi.com
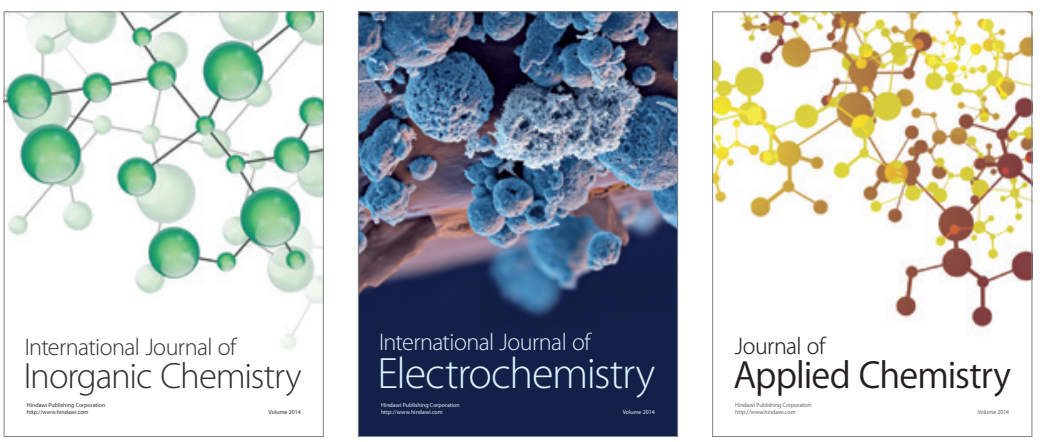

Journal of

Applied Chemistry
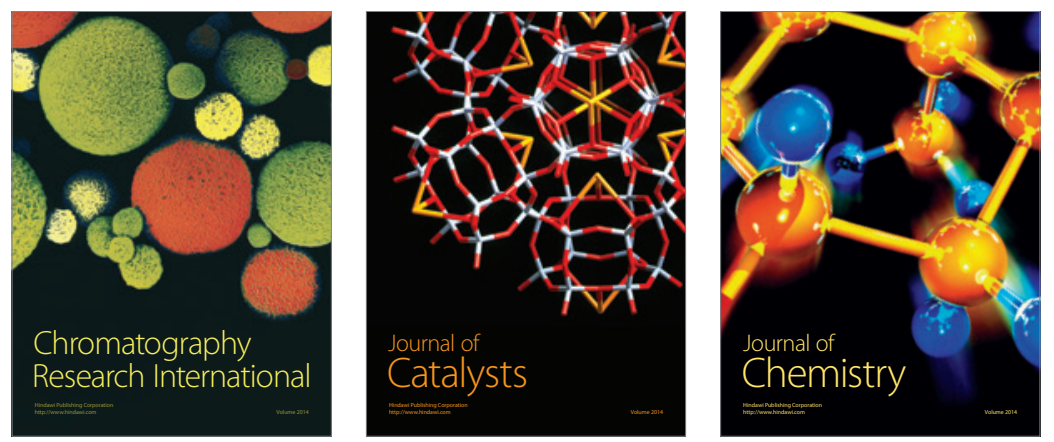
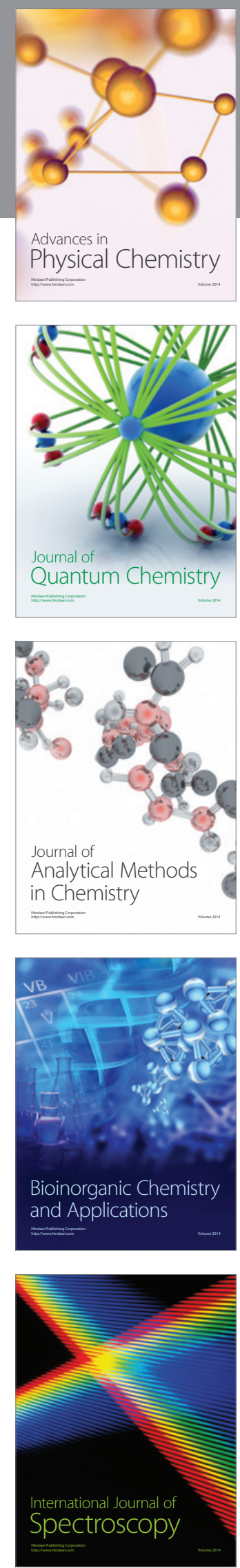